\title{
On the Ecological Theoretical Construction of Translation Studies
}

\author{
Yang Yufeng \\ Chinese Flight Test Establishment, Xi'an, Shaanxi, 710089
}

Keywords: translation ecology; ecological translation; ecological dimension; subjectivity

\begin{abstract}
The study of translation in the ecological dimension further reveals the differences between subjectivity and non-subjectivity, centralization and marginalization in translation. The article takes the distinction between ecological translation and translation ecology as the starting point, and emphasizes that the racial dimension of translation studies aiming at deconstructing the idea of racial superiority, so that inter-ethnic dialogues between translations are carried out among races and the ecology within the translation research system is maintained balance. The ecological dimension of translation studies has a difference in the study of translation awareness, embodying the interdisciplinarity and integration of translating theory in the context of postmodernism. The study of translation in the ecological dimension emphasizes the ecological imbalance and historical context in translation texts. Translation studies will certainly turn to the ecological direction and form an ecological translation perspective.
\end{abstract}

\section{Translation Ecology vs. Ecological Translation}

The interdisciplinary integration of ecology, ecological philosophy and translation studies has enriched the new perspective of translation studies. In 2003, the famous translation theorist and professor M. Cronin of Dublin City University in Ireland used the term "translation ecology" for the first time in his book Translation and Globalization. The name [1] advocates maintaining the balance of the translation ecosystem. Prof. Xu Jianzhong said in his translational ecology that "translation ecology is the mechanism and law of studying the interaction between translation and its surrounding ecological environment. Specifically speaking, it is the introduction of ecological research into translation studies, translation and its ecological environment is linked, and its mutual relations and its mechanism are in-depth research. From an ecological point of view, translation is studied and research is translated, and various phenomena in translation are sought to be analyzed and interpreted [2]. In 2004, Hubei Education Press published the translation theory monograph of Professor Hu Gengshen's Translation Adaptation and Choice Theory. This monograph is guided by Darwin's theory of adaptation and selection, and believes that translation is the translator's choice of activities to adapt to the translation ecological environment. At the same time, he repeatedly wrote his article explicitly to put forward his own views on the marriage between ecology and translation studies, and put forward the "ecological translation studies" and the "ecological turnaround" of translation studies [3]. Hu Gengshen believes that "Eco Translation Studies started in 2001 and was fully launched in 2009" [4]. "It is an ecological translation view, or an ecological approach to translation studies. It focuses on the wholeness of translation ecology, interprets the translation process from the perspective of the translation ecological environment, describes the relationship between the translator and the translation ecological environment, and focuses on the translator's living conditions and the development of translation capabilities. [5]

From the definition of the two concepts, we can see that they both focus on the key words of "ecology" and "ecological environment" and try to introduce new approaches to interdisciplinary studies. From the content point of view, the focus of both studies is different from the level of orientation. Eco-translatology advocates "translator-centredness", which is based on the ecological construction of translation theory and the translation environment within the overall ecosystem, and makes new translation ontologies from the perspective of translators. Description and interpretation, while translation ecology focuses on the interrelationship between translation and its environment, both seem to be microscopic and macroscopic. From a grammatical point of view, translation 
studies are the core words in "ecological translation studies." Ecology is a modifier, which can be understood as the exploration of translation from the perspective of ecology, with translation studies of languages, cultural translation studies, and cognitive translations. Studies and social translation studies belong to the category of translation studies, while "translation ecology" focuses on the exploration of ecological phenomena from the perspective of translation studies, with plant ecology, water ecology, mathematical ecology, behavioral ecology, urban ecology, etc. Branch disciplines belong to the category of ecology. In terms of etymology, the term "ecology" (Oikologie) was coined by Reiter in 1865 with the combination of two Greek words (researches) and oikos (houses, residences) [6]. The word oikos is Greek has the meaning of "home" and "homeland" [7]. The term "translation ecology" can be interpreted as "translator's house". There are many members in the family, including cognitive translation and social translation. Studies, etc., seem to have a broader category of translation ecology. It focuses on the harmonious operation of the entire ecological environment of the "translator's home", and is the subject of research on the internal structure of the translation ecosystem and its interrelationships. It is systematic, comprehensive and interdisciplinary. From the standpoint of translation studies, "ecological translation studies" seem more suitable as a branch of translation studies. Should it be classified as a "translator's house"?

\section{Racial Dimension- Colored Ethnic Culture Spine}

Race issues have far-reaching historical and cultural roots. Because of their particularity, blacks stand out in racial problems. Since the first blacks were shipped from Africa to the Americas in 1619, the identity, status, and language of blacks have gradually begun to disappear, and the blood and tears that blacks have fought have begun. The American civil war and the black people's rights movement in the 1960s greatly promoted the awakening and development of black consciousness. In Western translation, domestication translation has always occupied a dominant position. This translation strategy has, to some extent, impaired the construction of the cultural identity of disadvantaged peoples and races, thus making them marginalized and ruled and enslaved. Lawrence Venuti, a self-deconstructivist translation theorist, proposes an alienation translation. "The purpose is to highlight the foreign identity of the source language text, avoids the ideological dominance of the target language, and opposes the ethnocentrism of the target language culture to foreign texts. The tampering "was called for" picking up alienated translation weapons to resist the hegemonic acts of British and American cultures" [8]. Domestication and foreignization have always been at the pole of discourse power opposition. In essence, domestication and alienation are in translation. It plays an irreplaceable role and the two should co-exist and complement each other. The racial dimension of ecological translation is to dispel the binary opposition of translation in political ideology, to deconstruct and defeat the subjective idea of white superiority, to get the colored people out of the marginalized situation, and to realize the inter-ethnicity in the translation and communication of language and culture. Inter-temporal dialogues, in view of the various elements of translation, such as object, purpose, intention, and context, adopt naturalization and alienation selectively, which not only maintains cultural pluralism, but also maintains ethnic and ethnic independence. The realization of ecological balance in the dimension of race, thus maintaining the ecological balance of the translation system. The ecological translation of racial dimension recognizes the nature of the translation of the weak and strong foods in the context of post-colonialism. It attempts to reconstruct the balance of language and cultural ecosystems that have been broken by post-colonial contextual translation, and realizes the return of colored human culture to language translation. The contribution of colored people to the diversity of human civilization has enabled them to find their own cultural attributes and destinations. They are the spine of their adherence to, inheritance, and development of the essence of ethnic culture.

The liberation of colored people and women must begin with language because language plays an important role in the construction of race and gender. Language is a kind of symbol, a kind of symbol, and it is also a kind of symbol of status and the expression of right. In translation studies, especially in the translation field of ecological dimension, the translator's subjectivity plays an important role in the interactive subjectivity of translation. In translation studies, especially in the 
translation field of ecological dimension, the translator's subjectivity plays an important role in the interactive subjectivity of translation. The internals of the translation ecosystem are interrelated, affect each other and restrict, and the translator plays a role in harmonizing the balance of the translation ecosystem by exerting his subjective initiative. Based on the guiding ideology of ecological holism, from the perspective of the principles and purposes of ecological translation, in the interactive subjective translation, the purpose of translation lies in the successful completion of the translation process, thereby contributing to the continuation of the exchange and achieving a balanced translation ecological environment. When the subject is in the subjective position, the translator must be aware of the historical and cultural context in which the primitive was generated, the writing intention, the object, and the purpose of the original author in translating, thus deconstructing the gender discrimination in the original language when translatingracial discrimination, cultural hegemony and other factors that affect the harmony of translation and ecological environment, and realize and maintain the balance of the global cultural and ecological translation system. Inter-subjectivity plays an important role in ecological translation. There is no inter-subjectivity in the translation ecological environment. The existence of translator-centered theory is meaningless, and its existence has a certain "centrism" color. The deformation of the human-centered theory does not completely shake off the contradictory thinking of the binary opposition and is contrary to the guiding ideology of ecological holism.

\section{Future Prospects and Conclusion of Translation Studies}

The multiculturalism of today's world has influenced translation studies. Hu Genshen draws a map of translation ontology ecosystem and constructs a relatively complete translation ontology ecosystem. The ecological dimension of translation studies greatly expands the space for translation studies, and further reveals the differences between subjectivity and non-subjectivity, centralization and marginalization in translation. The racial dimension is the color of the spine, which helps them to persist, inherit and promote the essence of racial culture. The study of translation in the ecological dimension is an inevitable choice in the future of translation studies, and it will surely promote the development and prosperity of translation studies.

\section{References}

[1] Cronin, M. Translation and Globalization[M]. London: Routledge, 2003.

[2] Xu Jianzhong. Translation ecology [M]. Beijing: China Three Gorges Press, 2009: 3.

[3] Hu Genshen. Translation and Cross-cultural Communication: Integration and Innovation [M]. Shanghai: Shanghai Foreign Education Press, 2009:48.

[4] Hu Gengshen. Eco-translatology: The Background of Development and the Foundation of Development [J]. Foreign Language Studies, 2010 (4). 62-67.

[5] Hu Gengshen. Translation from the terminology ------ translation adaptation to the selection of a general view of [J]. Shanghai Translation, 2008 (2): 1-5.

[6] http://baike.baidu.com/view/71787.htm

[7] Glotfelty, C. \& Harold, F. The Ecocriticism Reader: Landmarks in Literary Ecology [M]. Athens: The University of Georgia Press 1996:69,140.

[8] Liu Zequan, Zhang Li. Alienation of Alienation: Reexamination of Venuti Theory[J]. Foreign Language Research, 2009 (3): 75-80. 